\title{
EMISSÕES DE DIÓXIDO DE CARBONO ADVINDAS DO CORTE DE ÁRVORES ISOLADAS NA FAZENDA BARREIRO NO MUNICÍPIO DE LIMEIRA DO OESTE-MG
}

\author{
CARBON DIOXIDE EMISSIONS FROM ISOLATED TREE CUTTING ON THE BARREIRO FARM \\ IN THE TOWN OF LIMEIRA DO OESTE-MG
}

\author{
Rodrigo Barbosa Lorena ${ }^{1}$, Carlos Roberto Sanquetta ${ }^{2}$, Ana Paula Dalla Corte ${ }^{3}$, \\ Osmar Luis Silva Vasconcelos ${ }^{4}$ \\ ${ }^{1}$ Universidade Brasil, Fernandópolis, São Paulo, Brasil-rodrigomeioambiente10@gmail.com \\ 2, 3,4 Universidade Federal do Paraná, Curitiba, Paraná, Brasil - carlossanquetta@gmail.com, \\ anapaulacorte@gmail.com \& osmarluisvasconcelos@gmail.com
}

\begin{abstract}
RESUMO
O objetivo deste artigo foi estimar as emissões de dióxido de carbono advinda do corte de árvores isoladas para o plantio de cana-de-açúcar e propor a compensação ambiental. O inventário foi realizado na Fazenda Barreiro, no município de Limeira do Oeste, estado de Minas Gerais. A propriedade possui uma área total de 74,01 hectares, sendo que 57,20 hectares foram avaliados neste estudo. No inventário foi catalogado o nome das espécies com nome cientifico e família botânica, foi medida a circunferência à altura do peito (CAP) e a altura comercial de cada árvore. Foi realizado cálculo do rendimento lenhoso a partir de equações da literatura. A massa das árvores foi estimada a partir da densidade básica encontrada literatura científica. A emissão em $\mathrm{CO}_{2 \text { eq }}$ (dióxido de carbono equivalente) foi calculada pela multiplicação da massa do fuste da árvore pelo teor de carbono (48\%) e pela constante estequiométrica 3,6667. As emissões de $\mathrm{CO}_{2}$ advindas do corte de árvores isoladas com rendimento de material lenhoso de $116,22 \mathrm{~m}^{3}$ foi de $132,99 \mathrm{t}$ de $\mathrm{CO}_{2}$ com média de 2,33 $\mathrm{t}$ de $\mathrm{CO}_{2}$ por hectare. Para realizar as medidas compensatórias a fim de zerar essas emissões será necessário o plantio de 659 mudas de árvores nativas. A partir do estudo realizado, conclui-se que o plantio florestal para a mitigação das emissões de dióxido de carbono é um fator relevante para se evitar o agravamento das mudanças climáticas.
\end{abstract}

PALAVRAS-CHAVE: Cana-de-açúcar, Carbono, Compensação ambiental.

\section{ABSTRACT}

The purpose of this article is to estimate the flow of carbon dioxide from the cutting of isolated trees for the planting of sugarcane and propose environmental compensation. The inventory was held at Barreiro Farm, in the town of Limeira do Oeste, state of Minas Gerais. The property has a total area of 74.01 hectares, of which 57.20 hectares were considered in this study. In the Inventory, the name of the species with scientific name and botanical family was cataloged, the circumference at breast height $(\mathrm{DBH})$ and the commercial height of each tree were measured. Wood yield calculation was performed using equations in the literature. The mass of the trees was estimated from the basic density found in the scientific literature. An emission in CO2eq (carbon dioxide equivalent) was obtained by multiplying the mass of the tree stem by the carbon content $(48 \%)$ and by the stoichiometric constant 3,666 . CO2 transfers from cutting trees fed with wood material yield of $116.22 \mathrm{~m}^{3}$ was $132.99 \mathrm{t} \mathrm{CO2}$ with an average of $2.33 \mathrm{t}$ $\mathrm{CO} 2$ per hectare. To carry out as compensatory measures in order to reset these necessary measures, it will be necessary to plant 659 seedlings of native trees. Based on the study, it is concluded that forest planting to mitigate so-called carbon dioxide is a relevant factor to avoid worsening climate change.

KEYWORDS: Sugarcane, Carbon, Environmental Compensation. 


\section{INTRODUÇÃO}

Acredita-se que as ações antrópicas tenha elevado a temperatura média do planeta em $1,0^{\circ} \mathrm{C}$ de aquecimento global em relação ao período pré-industrial, variando entre $0,8^{\circ} \mathrm{C}$ a $1,2^{\circ} \mathrm{C}$, sendo possível que chegue a um aumento de $1,5^{\circ} \mathrm{C}$ entre 2030 e 2052 se for mantido o ritmo atual de emissões de GEE (IPCC, 2019). As mudanças climáticas causariam impactos para setores vitais da economia, relacionados à disponibilidade de recursos hídricos, geração de energia, produtividade agrícola e para as populações das cidades costeiras (CMMC, 2013).

O inventário de emissões de gases de efeito estufa (GEE) é um mecanismo que permite estimar as emissões de GEE do setor empresarial e governamental como um todo (SANQUETA et al., 2013, NUNNENKAMP \& CORTE, 2017). As emissões de GEE têm aumentado nas últimas décadas, em que "as emissões globais de Gases de Efeito Estufa (GEE), entre 1970 e 2004, cresceram 70\% "(PBMC, 2014).

O Brasil tem apresentado redução nas suas emissões de $\mathrm{CO}_{2 \mathrm{e}}$ de 1,71 bilhão de $\mathrm{tCO}_{2 \text { eq }}$ em 1990 para 1,54 bilhão de tCO2eq em 2017, queda acumulada de $10 \%$ nas emissões (SERENO \& ANDRADE, 2020), porém esse cenário pode ser afetado com as queimadas do pantanal no ano de 2020 que registrou no mês de outubro 2.856 focos de incêndios, sendo o maior índice desde que começou a série histórica em 1998 (INPE, 2020). O Brasil apresentou suas contribuições nacionalmente determinadas (NDC) com o compromisso de reduzir as emissões de gases de efeito estufa em $37 \%$ abaixo dos níveis de 2005 , em 2025 , com uma contribuição subsequente de reduzir as emissões de gases de efeito estufa em $43 \%$ abaixo dos níveis de 2005 , em 2030 (NDC, 2016).

A mudança do uso do solo é responsável por $27,5 \%$ das emissões totais de $\mathrm{CO}_{2 \mathrm{e}}$ (MCTIC, 2016). Isso se deve a aptidão agrícola do Brasil, onde 7,6\% do seu território é utilizado para produção de culturas agrícolas (NASA, 2017). Dentre as culturas plantadas e segundo a companhia nacional de abastecimento 8.590 .000 hectares é destinado ao plantio de cana-de-açúcar, considerando a safra 2018/2019, uma redução de $1,6 \%$ em relação à safra 2017/2018 (CONAB, 2019). O Brasil respondeu por cerca de $61,8 \%$ das exportações mundiais de açúcar, o estado de São Paulo possui a maior produção de cana-de-açúcar, em seguida aparecem Goiás e Minas Gerais (FONTANETTI \& BUENO, 2017).

Entre os problemas relacionados com a implantação da cana-de-açúcar, se destacam a queima antes do corte da cana, degradação do solo, poluição das águas, ameaça a outras culturas e áreas de vegetação nativas, utilização de defensivos agrícolas, destruição de áreas especialmente protegidas (COELHO et al., 2007; NOEL, 2007; GOLDEMBERG et al., 2008; MARTINELLI e FILOSO, 2008; WWF, 2008, JORDÃO \& MORETTO, 2015). As árvores

realizam a absorção de dióxido de carbono por meio da fotossíntese, ficando armazenado na biomassa. Quando ocorre o corte desta árvore além de parar de absorver dióxido de carbono, por meio da decomposição ou queimada ocorre a liberação na atmosfera do estoque de carbono armazenado nela (JAYACHANDRAN, 2017).

A compensação ambiental das emissões de dióxido de carbono, totais ou parciais é uma medida voluntária, que busca neutralizar as emissões através da remoção ou redução externa (NUNNENKAMP \& CORTE, 2017). A compensação ambiental está colocada no âmbito do usuário pagador. A ideia do usuário pagador está na de que aquele que faz uso dos recursos naturais venha a sofrer a incidência de um valor (econômico) devido a utilização dos recursos naturais (MOTA, 2015).

Com a grande expansão da cana-de-açúcar, verifica-se a necessidades de estudos relacionados aos impactos advindos dessa expansão principalmente do corte de árvores isoladas, fazendo que este estudo seja um meio importante de medir os impactos nas mudanças climáticas dessa intervenção.

Com isso, o presente estudo teve como objetivo realizar a estimativa das emissões de $\mathrm{CO}_{2}$ advinda do corte de árvores isoladas na Fazenda Barreiro no município de Limeira do Oeste no estado de Minas Gerais e realizar uma proposta de compensação ambiental baseada no plantio florestal.

\section{MATERIAL E MÉTODOS}

\section{Área de estudo}

A Fazenda Barreiro localizada no município de Limeira do Oeste, no estado de Minas Gerais, apresenta uma área total de 74,01 hectares, destes, 57,20 hectares foram avaliados quanto ao o corte de árvores isoladas. O imóvel está localizado no Bioma Mata Atlântica nas coordenadas $19^{\circ} 21^{\prime} 27.20^{\prime \prime S}$ e $50^{\circ} 35^{\prime} 22.45^{\prime \prime O}$ (IDE-SISEMA, 2020), conforme Figura 1, está localizado no Bioma Mata Atlântica porém está na faixa de transição deste Bioma para o Bioma Cerrado, possuindo vegetação com características de transição de biomas.

\section{Densidade Básica, Biomassa, Teor de Carbono e Cálculo das emissões de Dióxido de Carbono}

Para a obtenção da densidade básica por espécie foi feita pesquisa em publicações científicas presentes na Tabela 1. 


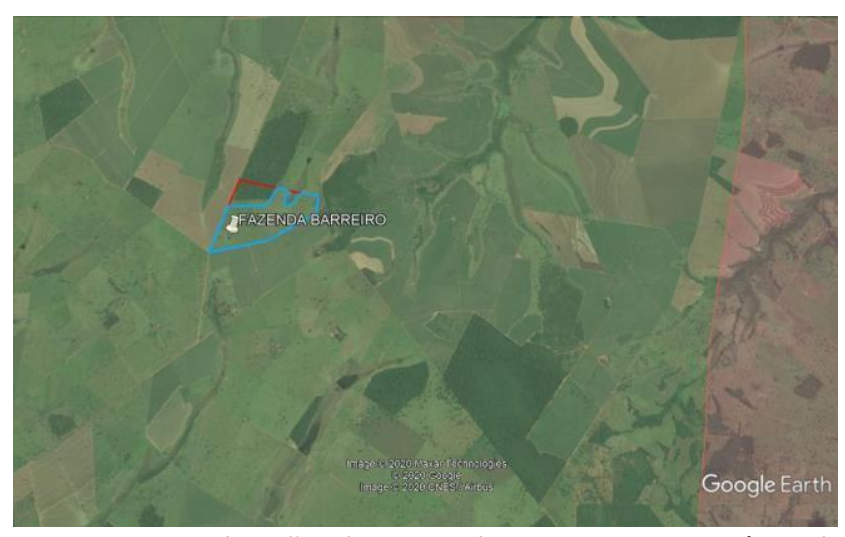

Figura 1. Localização da Fazenda Barreiro, município de Limeira do Oeste, MG. Áreas em verde representam o Bioma Mata Atlântica e em marrom o Bioma Cerrado.

Os solos predominantes no município são Latossolo vermelho distrófico típico, com textura argilosa, epieutrófico, fase campo subtropical relevo suave ondulado (LVd1) e Gleissolo melânico distrófico típico $A$ proeminente textura argilosa (GMd4) (IDE-SISEMA, 2020).

\section{Coleta de dados}

Em uma área de 57,20 hectares foi realizado o levantamento de todas as árvores isoladas através do censo florestal.

Foram contabilizados 90 indivíduos arbóreos, foi realizada a identificação da espécie (nome científico) e respectiva família botânica. Foi medida a circunferência à altura do peito (CAP), a 1,30 m de altura, com auxílio de uma fita métrica, evitando protuberâncias. Foram amostrados todos os indivíduos com diâmetro igual ou superior a $5 \mathrm{~cm}$ (DAP $\geq 5 \mathrm{~cm}$ ).

\section{Cálculo do rendimento do volume de madeira}

Para o cálculo do volume de material lenhoso foi utilizada a equação volumétrica específica para nativas que apresentem a fitofissionomia campo cerrado (SOARES et al., 2012), devido à vegetação apresenta característica do bioma cerrado.

- Volume $\left(\mathrm{m}^{3}\right)$ com casca do fuste: $V F C C=0,000315 \times D A P^{1,746205} \times H c^{0,274972}$

- Volume $\left(\mathrm{m}^{3}\right)$ com casca dos galhos:

$V G C C=0,000003 \times D A P^{3,512808} \times H c^{-0,101337}$

Em que: DAP: diâmetro à altura do peito $(\mathrm{cm})$; Hc: altura comercial (m).

Para a obtenção da biomassa individual foi multiplicado o volume de madeira pela densidade básica da referida espécie, presente na Tabela 1.

O teor de carbono utilizado foi o valor default da indicação do IPCC (2006) que para floresta tropical e subtropical para DAP maior que $10 \mathrm{~cm}$ é de $49 \%$. As emissões de $\mathrm{CO} 2$ foram encontradas conforme as fórmulas descritas abaixo, adaptado de (IPCC, 2003).

Tabela 1. Densidade básica com a devida fonte bibliográfica e volume de material lenhoso calculado.

\begin{tabular}{|c|c|c|c|c|}
\hline Espécie & $\begin{array}{l}\text { Número } \\
\text { de árvores }\end{array}$ & $\begin{array}{c}\text { Fonte da } \\
\text { densidade básica }\end{array}$ & Densidade básica $\left(\mathrm{kg} / \mathrm{m}^{3}\right)$ & $\begin{array}{l}\text { Total do volume } \\
\text { da madeira }\left(\mathrm{m}^{3}\right)\end{array}$ \\
\hline Anadenanthera macrocarpa (Benth.) Brenan. & 2 & Williams et al. (2001) & 1.050 & 2,13 \\
\hline Aspidosperma macrocarpon Mart. \& Zucc. & 7 & Neto et al. (2015) & 500 & 10,20 \\
\hline Blepharocalyx salicifolius (Kunth) O. Berg. & 1 & Lorenzi (1998) & 760 & 1,55 \\
\hline Chlorophora tinctoria (L.) Gaudich. ex B. D. Jackson & 1 & Lorenzi (1992) & 880 & 1,09 \\
\hline Copaifera langsdorffii Desf. & 4 & Lorenzi (1992) & 700 & 7,87 \\
\hline Dipteryx alata Vogel. & 14 & Sano et al. (2004) & 1.100 & 17,30 \\
\hline Ficus insipida Willd. & 3 & Parolin \& Ferreira (1998) & 380 & 3,96 \\
\hline Myroxylon peruiferum L.f. & 1 & Lorenzi (1992) & 950 & 1,75 \\
\hline Palicourea rigida Kunth. & 2 & Vale et al. (2002) & 430 & 2,76 \\
\hline Phytolacca dioica $\mathrm{L}$. & 2 & Horak (1981) & 730 & 2,76 \\
\hline Qualea grandiflora Mart. & 39 & Neto et al. (2015) & 480 & 48,07 \\
\hline Sclerolobium aureum var. Velutinum Benth. & 4 & Neto et al. (2015) & 610 & 4,89 \\
\hline Tabebuia avellanedae Toledo. & 4 & Lorenzi (1992) & 1.030 & 4,88 \\
\hline Zanthoxylum rhoifolium Lam. & 5 & Missio et al. (2017) & 440 & 5,81 \\
\hline
\end{tabular}


- Vol.da madeira $\left(\mathrm{m}^{3}\right) \times$

Densidade Básica da madeira $\left(\mathrm{Kg} / \mathrm{m}^{3}\right)$

- Biomassa $(\mathrm{kg}) \times$ Teor de carbono $(49 \% / 100)$

- Carbono estocado $(\mathrm{kg}) \times \mathrm{CO}_{2 e}(3,6667)$

\section{Compensação Ambiental}

A proposta de compensação ambiental foi a de reposição florestal. Para isso foram utilizados dois cenários, o de plantio de florestas nativas, visando à recuperação ambiental de áreas degradadas, e o de plantio comercial onde existe a possibilidade de comercialização da madeira.

\section{RESULTADOS E DISCUSSÃO}

De 90 indivíduos arbóreos levantados no censo florestal apenas 1 indivíduo arbóreo não foi identificado, a espécie com maior presença foi a Qualea grandiflora com 39 indivíduos. Foi computado um valor total de $116,22 \mathrm{~m}^{3}$ de material lenhoso, ou seja, 2,03 $\mathrm{m}^{3}$.ha-1 ou uma média de $1,29 \mathrm{~m}^{3}$ por indivíduo. As espécies que apresentaram maior e menor volume de material lenhoso foram Qualea grandiflora e Chlorophora tinctoria com 48,07 $\mathrm{m}^{3}$ e 1,09 $\mathrm{m}^{3}$ respectivamente.

Um estudo realizado por Paula et al. (1998) no Bioma Cerrado do Município de Santa Quitéria no Maranhão, identificou em um levantamento quantitativo com uma média de $0,057 \mathrm{~m}^{3}$ de material lenhoso. Nota-se que o volume médio de material lenhoso na Fazenda Barreiro esteve acima do resultado obtido por Paula et al. (1998), possivelmente devido que a Fazenda Barreiro se encontra em área de transição de Biomas entre o Cerrado e a Mata Atlântica e por isso apresenta indivíduos arbóreos de maior porte, pois possuía árvores característica de ambos os Biomas por isso alguns desses indivíduos arbóreos tiveram um rendimento de material lenhoso maior que os encontrados em áreas tipicamente do Bioma Cerrado.

De acordo com Sano et al. (2004), a espécie Dipteryx alata apresentou uma densidade básica de $1.100 \mathrm{~kg} \cdot \mathrm{m}^{-3}$ sendo a maior das espécies encontrada na Fazenda Barreiro e segundo Parolin e Ferreira (1998) a densidade da Ficus insipida é de $380 \mathrm{~kg} / \mathrm{m}^{3}$, sendo a menor densidade das espécies encontrada na Fazenda Barreiro. Silva et al. (2015) foi feito um estudo no cerrado do estado do Tocantins e obtiveram uma densidade média de $650 \mathrm{~kg} / \mathrm{m}^{3}$ da madeira. A densidade total da madeira da Fazenda Barreiro foi de $57.330 \mathrm{~kg} / \mathrm{m}^{3}$, sendo que a média individual foi de 644,16 $\mathrm{kg} / \mathrm{m}^{3}$.

Nota-se que as médias de densidade da Fazenda Barreiro e da realizada por Silva et al. (2015) estão bem próximas assegurando com isso que a pesquisa realizada para se encontrar a densidade presente na Tabela 1 está condizente.

Obtidas as informações a respeito da densidade básica da espécie com respectivo cálculo de rendimento de material lenhoso foi possível se encontrar a biomassa da madeira.

Por fim, para se encontrar o total do carbono estocado em $(\mathrm{kg})$ e o total do $\mathrm{CO}_{2}$ por espécime $(\mathrm{kg})$ foram feitos cálculos informados no item de Material e Métodos, os resultados estão presentes na Tabela 2.

A biomassa é o meio mais eficaz de se conhecer o carbono estocado (MARCOS et al., 2020), a biomassa total encontrada na Fazenda Barreiro foi de 74,02 t com uma média de 1,29 t.ha ${ }^{-1}$. De acordo Rezende et al. (2006), a biomassa lenhosa verde encontrada em uma vegetação do Cerrado na Fazenda Água Limpa em Brasília no Distrito Federal foi de 2,23 t.ha ${ }^{-1}$. Um dos motivos da maior biomassa no estudo de Rezende et al. (2006) pode ser que no seu estudo foi contabilizado um maior rendimento lenhoso com $2,83 \mathrm{~m}^{3}$.ha ${ }^{-1}$, que acabou influenciando diretamente no resultado da biomassa total.

Um estudo feito por Vieira et al. (2009) verificou que o teor de carbono médio é de $42,09 \%$ no cerrado e $44,81 \%$ na Caatinga ambas no estado da Bahia nos municípios de Campo Alegre de Lourdes, Remanso e Casa Nova. Conforme observado o valor default do IPCC (2006) de $49 \%$ é maior que o encontrado nos biomas cerrado e caatinga, provavelmente pelo fato do IPCC utilizar o valor default baseado em florestas tropicais.

$\mathrm{Na}$ Fazenda Barreiro foi quantificado cerca $36,27 \mathrm{t}$ de carbono estocado, com uma média de 0,63 t.ha ${ }^{-1}$ de carbono estocado. No estudo realizado por Rezende et al. (2006), foi quantificado cerca de 0,54 t.ha ${ }^{-1}$ de carbono estocado. Em ambos os casos existe uma quantificação muito próxima do carbono estocado, porém a Fazenda Barreiro possui um índice maior de carbono estocado, possivelmente por estar em área de transição de Biomas e algumas espécies arbóreas presente nesta área apresentaram rendimento lenhoso superior ao presente em áreas típicas de cerrado como o caso estudado por Rezende et al. (2006). O estoque de carbono no Bioma Amazônico é bem maior do que quantificadas no Bioma Cerrado, com cerca de 177 t.ha $^{-1}$ de carbono na biomassa de troncos e galhos de árvores DAP igual ou superior a $5 \mathrm{~cm}$ (HIGUCHI \& CARVALHO, 1994, PAIVA et al., 2011), devido a suas espécies arbóreas serem de grande porte é natural que o estoque de carbono nesse Bioma seja elevado. 
Tabela 2. Total da biomassa da madeira em $(\mathrm{kg}$ ), total de teor de carbono $49 \%$, total de carbono estocado, 3,6667 conforme (SANQUETTA et al., 2014) e total do valor do $\mathrm{CO}_{2 \mathrm{e}}$ por espécime $(\mathrm{kg})$.

\begin{tabular}{|c|c|c|c|c|c|}
\hline Espécie & $\begin{array}{l}\text { Biomassa da } \\
\text { madeira (kg) }\end{array}$ & $\begin{array}{c}\text { Teor de } \\
\text { carbono } 49 \%\end{array}$ & $\begin{array}{c}\text { Carbono } \\
\text { estocado (kg) }\end{array}$ & $\mathrm{CO}_{2} \mathrm{e}$ & $\begin{array}{c}\mathrm{CO}_{2 \mathrm{e}} \text { por } \\
\text { espécime }(\mathrm{kg})\end{array}$ \\
\hline Anadenanthera macrocarpa (Benth.) Brenan. & $2.236,50$ & 0,49 & $1.095,89$ & 3,6667 & $4.018,28$ \\
\hline Aspidosperma macrocarpon Mart. \& Zucc. & $5.100,00$ & 0,49 & $2.499,00$ & 3,6667 & $9.163,08$ \\
\hline Blepharocalyx salicifolius (Kunth) O. Berg. & $1.178,00$ & 0,49 & 577,22 & 3,6667 & $2.116,49$ \\
\hline Chlorophora tinctoria (L.) Gaudich. ex B. D. Jackson & 959,20 & 0,49 & 470,01 & 3,6667 & $1.723,38$ \\
\hline Copaifera langsdorffii Desf. & $5.509,00$ & 0,49 & $2.699,41$ & 3,6667 & $9.897,93$ \\
\hline Dipteryx alata Vogel. & $19.030,00$ & 0,49 & $9.324,70$ & 3,6667 & $34.190,88$ \\
\hline Ficus insipida Willd. & $1.504,80$ & 0,49 & 737,35 & 3,6667 & $2.703,65$ \\
\hline Myroxylon peruiferum L.f. & $1.662,50$ & 0,49 & 814,63 & 3,6667 & $2.986,99$ \\
\hline Palicourea rigida Kunth. & $1.186,80$ & 0,49 & 581,53 & 3,6667 & $2.132,30$ \\
\hline Phytolacca dioica $\mathrm{L}$. & $2.014,80$ & 0,49 & 987,25 & 3,6667 & $3.619,96$ \\
\hline Qualea grandiflora Mart. & $23.073,60$ & 0,49 & $11.306,06$ & 3,6667 & $41.455,94$ \\
\hline Sclerolobium aureum var. Velutinum Benth. & $2.982,90$ & 0,49 & $1.461,62$ & 3,6667 & $5.359,33$ \\
\hline Tabebuia avellanedae Toledo. & $5.026,40$ & 0,49 & $2.462,94$ & 3,6667 & $9.030,85$ \\
\hline Zanthoxylum rhoifolium Lam. & $2.556,40$ & 0,49 & $1.252,64$ & 3,6667 & $4.593,04$ \\
\hline Total das emissões de $\mathrm{CO}_{2} \mathrm{e}$ & & & & & $132.992,09$ \\
\hline
\end{tabular}

Em povoamentos de Eucalyptus grandis com 6 anos de idade calcularam um estoque médio de carbono para fuste sem casca e galhos de 42,73 t.ha-1 (PAIXÃO et al., 2006; PAIVA et al., 2011), possui um estoque de carbono mais próximo ao valor encontrado na Fazenda Barreiro o que o torna uma das espécies indicadas para plantio em possíveis projetos florestais para a realização da compensação ambiental das emissões de dióxido de carbono.

As emissões advindas da supressão de árvores isoladas na Fazenda Barreiro somadas totalizaram 132.992,09 kg de $\mathrm{CO}_{2}$ e ou $132,99 \mathrm{t}$ de $\mathrm{CO}_{2}$ e, média de 2,33 t.ha ${ }^{-1} \mathrm{CO}_{2}$ e. $\mathrm{A}$ espécie que apresentou maior emissão foi a Qualea grandiflora com 41,46 t de $\mathrm{CO}_{2}$ e a menor emissão foi a espécie Chlorophora tinctoria com 1,72 t de $\mathrm{CO}_{2}$ e. $\mathrm{O}$ cálculo das emissões média de t.ha ${ }^{-1} \mathrm{CO}_{2}$ e ajudam a perceber que mesmo o corte de poucas árvores isoladas tem o potencial de agravar as mudanças climáticas e servem de alerta para a necessidade de medidas que venham mitigar essas emissões.

Comparativamente com o Bioma Amazônico as emissões quantificadas na Fazenda Barreiro são bem inferiores, um estudo realizado por Campos (2012) para calcular as emissões de dióxido de carbono da madeira Cerrada da Amazônia quantificou um total de emissões entre 7,5 t CO $\mathrm{CO}_{2}$ e 28,4 $\mathrm{t} \mathrm{CO}_{2}$ por tora. Tendo em conta o teor de carbono presente em árvores do Bioma Amazônico os efeitos para as mudanças climáticas do corte de árvores neste Bioma é muito mais grave.
Verifica-se que existe uma relação direta entre emissões de gases de efeito estufa e rendimento de material lenhoso, pois a Qualea grandiflora foi a que obteve um maior rendimento de volume de madeira e maior emissão e a Chlorophora tinctoria foi a que teve menor rendimento de volume de madeira e apresentou as menores emissões de dióxido de carbono, o mesmo de verifica em relação à biomassa encontrada.

A cana-de-açúcar é uma cultura com grande potencial de utilização através da produção do álcool combustível e da cogeração de energia através do uso do uso do bagaço em caldeiras (RESENDE et al., 2001), o que com certeza ajuda na redução das emissões de dióxido de carbono através da utilização de um combustível e energia mais limpa e renovável, porém as emissões de dióxido de carbono advindos do corte de árvores isoladas podem prejudicar os benefícios advindos da utilização do álcool e da biomassa da cana-de-açúcar.

Constatou-se que o corte de árvores isoladas na Fazenda Barreiro como preparação para o plantio decana- de-açúcar gerou emissões de dióxido de carbono agravando o cenário das mudanças climáticas e foi reaizada uma porposta voluntaria de medidas de compensação ambiental baseada no plantio de mudas de árvores para mitigar essas emissões.

\section{Proposta de Compensação Ambiental}

A compensação ambiental das emissões de dióxido de 
carbono, totais ou parciais é uma medida voluntária, que busca neutralizar as emissões através da remoção ou redução externa (NUNNENKAMP \& CORTE, 2017), tendo em vista as emissões de dioxido de carbono advindo do corte de árvores isoladas para o plantio de cana-de-açúcar, medidas que venham compensar essas emissões são de grande importância para garantir a sustentabilidade do setor sucro alcooleiro.

Uma possibilidade de realizar a compensação dessas emissões de dioxido de carbono é através do plantio de mudas de árvores. De acordo com Wolf et al. (2012), os projetos de reflorestamento auxiliam na redução da emissão dos gases causadores de efeito estufa, realizando a absorção do dióxido de carbono além de realizar a prestação de diversos serviços ambientais, econômicos e sociais para a sociedade.

A execução de projetos de reposição florestal é um fator importante para possibilitar um aumento na quantidade de estoque de carbono, pois o carbono fica estocado nas espécies arbóreas e favorece na mitigação das consequências das mudanças climáticas (AZEVEDO et al., 2018). Para calculos da compensação que pode ser realizada na Fazenda Barreiro foram utilizados cenários florestais desenvolvidos por Flizikowski (2012) conforme demonstrado na Tabela 3.

Tabela 3. Cenários para compensação de emissões de $\mathrm{CO}_{2}$.

\begin{tabular}{|c|c|c|c|}
\hline Modelo & Gêneros & Espaçamento & Árvore \\
\hline 1 & Eucalyptus & $2,5 \mathrm{~m} \times 2,5 \mathrm{~m}$ & 1.242 .917 \\
\hline 2 & Eucalyptus & $3,0 \mathrm{~m} \times 2,0 \mathrm{~m}$ & 1.211 .303 \\
\hline 3 & Eucalyptus & $3,0 \mathrm{~m} \times 3,0 \mathrm{~m}$ & 1.102 .282 \\
\hline 4 & Pinus & $2,5 \mathrm{~m} \times 2,5 \mathrm{~m}$ & 362.292 \\
\hline 5 & Pinus & $3,0 \mathrm{~m} \times 2,0 \mathrm{~m}$ & 339.464 \\
\hline 6 & Pinus & $3,0 \mathrm{~m} \times 3,0 \mathrm{~m}$ & 278.070 \\
\hline 7 & Nativa & $3,0 \mathrm{~m} \times 2,0 \mathrm{~m}$ & 590.311 \\
\hline
\end{tabular}

Fonte: adaptado de Flizikowski (2012).

Flizikowski (2012) realizou uma pesquisa cuja emissão

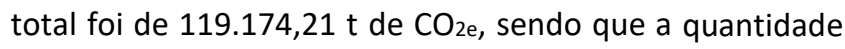
de árvores e as emissões totais de dióxido de carbono foram identificadas, calculou-se o fator de fixação de carbono.

$$
F f=E t / N
$$

$F f=$ fator de fixação de carbono ( $\mathrm{tCO}_{2 \mathrm{e}}$ por árvore); $E t=$ emissão total ( $\mathrm{t}$ de $\mathrm{CO}_{2 \mathrm{e}}$ ); e $\mathrm{N}=$ número de árvores a serem plantadas.

A partir do inventário de emissões de dióxido de carbono, foi possível calcular o númenro de árvores necessárias para compensar as emissões. Os fatores de fixação da Tabela 4 foram calculados com base em Flizikowski (2012), conforme demonstrado na Tabela 3. O número de árvores a serem plantadas considerou as emissões totais que foram calculadas no inventário de emissões da Fazenda Barreiro de 132,99 t de CO2.

Tabela 4. Fatores de fixação de carbono e número de árvores a serem plantadas.

\begin{tabular}{ccc}
\hline Modelo & $\begin{array}{c}\text { Fator de fixação de carbono } \\
\text { (tCO2e por árvore) }\end{array}$ & $\begin{array}{c}\text { Número de árvores a } \\
\text { serem plantadas }\end{array}$ \\
\hline 1 & 0,0958 & 1.388 \\
\hline 2 & 0,0983 & 1.353 \\
\hline 3 & 0,1080 & 1.231 \\
\hline 4 & 0,3286 & 405 \\
\hline 5 & 0,3507 & 379 \\
\hline 6 & 0,4282 & 311 \\
\hline 7 & 0,2017 & 659 \\
\hline
\end{tabular}

Através da fotossíntese os ecossistemas florestais se tornam importantes meios de absorção de dióxido de carbono atmosférico. Por isso, o desflorestamento pode ser tido como um dos principais responsáveis pelo aumento das emissões de gás carbônico na atmosfera (REBOITA et al., 2014). Essa situação releva a necessidade da recuperação de áreas que foram desflorestadas, tendo como objetivo proporcionar a absorção de dióxido de carbono e aumentar o seu estoque em indivíduos arbóreos (JOLY et al., 2014).

Nos dias de hoje, devido aos riscos advindo das mudanças climáticas, a fixação de carbono da atmosfera passou a ser considerado um grande benefício proporcionado pelas florestas (MELO \& DURIGAN, 2006; MIRANDA et al., 2011). Os cenários de reposição florestal contido na Tabela 4, apesar de oferecer as possibilidades de plantio para fins comerciais como é o caso do Eucalyptus e Pinus possui como principal objetivo a absorção de deoxido de carbono para realizar a compensação ambiental do corte de árvores isoladas.

\section{Conclusões}

Em face dos resultados obtidos é possível constatar que o corte de 90 árvores isoladas realizado na Fazenda Barreiro em uma área de 57,20 hectares para o plantio de cana-de açúcar, com um rendimento do material lenhoso de 116,22 $\mathrm{m}^{3}$ levou a uma emissão de 132,99 t de $\mathrm{CO}_{2}$, média de 2,33 t.ha ${ }^{-1}$ de $\mathrm{CO}_{2}$. A compensação ambiental das emissões de dióxido de carbono é de caráter voluntário, para realizar a compensação dessas emissões visando compensá-las foram 
realizados alguns modelos de plantio.

A partir dos modelos propostos, o empreeemdedor poderá escolher qual desses modelos de compensação ambiental se enquadra na sua possibilidade ou possui um maior retorno custo beneficio, que são os modelos de plantio comercial e de espécies nativas. Para a compensação de floresta nativa que seria para a recuperação do bioma em que ocorreu a supressão será necessário o plantio de 659 árvores nativas conforme equação 7 da Tabela 4, tendo em vista realizar a compensação ambiental das emissões de dióxido de carbono e com vista para o aproveitamento econômico do material lenhoso, a equação 3 da Tabela 4 apresenta uma necessidade de plantio de Eucalyptus de 1.231 árvores e a equação 6 da Tabela 4 apresenta uma necessidade de plantio florestal comercial de Pinus de 311 árvores.

\section{REFERÊNCIAS}

AZEVEDO, A.D.D. et al. Estoque de carbono em áreas de restauração florestal da Mata Atlântica. Floresta, v.48, n.2, p.183194, 2018.

CAMPOS, É.F.D. Emissões de $\mathrm{CO}_{2}$ da madeira cerrada da amazônia: o caso da exploração convencional. 2012. 172p. (Dissertação de mestrado).

CMMC - COMISSÃO MISTA PERMANENTE SOBRE MUDANÇAS CLIMÁTICAS. Lesgilação brasileira sobre mudanças climáticas. 2013. Disponível em: http://www.senado.leg.br/comissoes/ CMMC/Livro_legislacao_ambiental_Completo_Final_17_09_201 3.pdf

CONAB - COMPANHIA NACIONAL DE ABASTECIMENTO. Acompanhamento da safra brasileira cana-de-açúcar. OBSERVATÓRIO AGRÍCOLA, v.5, n.4, p.1-75, 2019.

FLIZIKOWSKI, L.C. Estimativa de emissões de dióxido de carbono na construção civil e neutralização com espécies florestais: um estudo de caso. 2012. 132p. (Dissertação de mestrado)

FONTANETTI, C.S.; BUENO, O.C. Cana-de-açúcar e seus impactos: uma visão acadêmica. Bauru: Canal 6, 2017.

HORAK, K.E. The Developmental anatomy of stegnosperma (Phytolaccaceae). 1981. 126p. (Dissertação de mestrado).

IDE-SISEMA. WebGIS - IDE-Sisema. IDE-Sisema: WebGIS, 2020. Disponível em: http://idesisema.meioambiente.mg.gov.br

INPE - INSTITUTO NACIONAL DE PESQUISAS ESPACIAIS. Monitoramento dos focos ativos por bioma: comparação do total de focos ativos detectados pelo satélite de referência em cada mês, no período de 1998 até 31/10/2020. 2020. Disponível em: http://queimadas.dgi.inpe.br/queimadas/portal-static/ estatisticas_estados/

IPCC - INTERGOVERNMENTAL PANEL ON CLIMATE CHANGE. Good practice guidance for land use, land-use change and forestry. 2003.
IPCC - INTERGOVERNMENTAL PANEL ON CLIMATE CHANGE. Agriculture, forestry and other land use. 2006.

IPCC. INTERGOVERNMENTAL PANEL ON CLIMATE CHANGE. SPM Sumário para SPM formuladores de política. 2019.

JAYACHANDRAN, S. et al. Cash for carbon: A randomized trial of payments for ecosystem services to reduce deforestation. Science, p.267-273, 2017.

JOLY, C.A. et al. Experiences from the Brazilian Atlantic Forest: ecological findings and conservation initiatives. New Phytologist v.204, n.3, p.1-15, 2014.

JORDÃO, C.O.; MORETTO, E.M. A vulnerabilidade ambiental e o planejamento territorial do cultivo de cana-de-açúcar. Ambiente \& Sociedade, v.18, n.1, p.81-98, 2015.

LORENZI, H. Árvores brasileiras manual de identificação e cultivo de plantas arbóreas nativas do Brasil. Nova Odessa: Plantarum, v.1, 1992

LORENZI, H. Árvores brasileiras manual de identificação e cultivo de plantas arbóreas nativas do Brasil. Nova Odessa: Plantarum, v.2, 1998 .

MARCOS, D.P. et al. Compartimentação do estoque individual de carbono em uma plantação comercial de erva-mate. BIOFIX Scientific Journal, v.5, n.2, p.168-173, 2020.

MCTIC - MINISTERIO DA CIÊNCIA, TECNOLOGIA, INOVAÇÕES E COMUNICAÇÃO. Estimativas anuais de emissões de gases de efeito estufa no Brasil. 3.ed., 2016. Disponível em: https://sirene.mctic.gov.br/portal/export/sites/sirene/backend/ga leria/arquivos/2018/10/11/Estimativas_3ed.pdf

MIRANDA, D.L.C.D. et al. Equações alométricas para estimativa de biomassa e carbono em árvores de reflorestamentos de restauração. Revista Árvore, v.35, n.3, p.679-689, 2011.

MISSIO, F.D.F. et al. Atributos funcionais de espécies arbóreas em um fragmento de floresta ombrófila mista em Lages - SC. Ciência Florestal, v.27, n.1, p.215-224, 2017.

MOTA, A função socioambiental da propriedade: a compensação ambiental como decorrência do princípio do usuário pagador. Revista de Direito da Cidade, v.7, n.2, p.776-803, 2015.

NASA - NATIONAL AERONAUTICS AND SPACE ADMINISTRATION USGS (SCIENCE FOR A CHANGING WORLD). Western Geographic Science Center, 2017. Disponível em: https://www.usgs.gov/centers/wgsc/science/global-food-securitysupport-analysis-data-30-m?qt-science_center_objects=0\#qtscience center_objects

NDC. Pretendida contribuição nacionalmente determinada. 2016. Disponivel em: http://www.itamaraty.gov.br/images/ed_ desenvsust/BRASIL-iNDC-portugues.pdf

NETO, A.D.P.M. et al. Densidade e poder calorífico como base para prevenção de incêncios florestais sob linhas de transmissão. Nativa Sinop Pesquisas Agrárias e Ambientais, v.3, p.10-15, 2015.

NUNNENKAMP, C.H.; CORTE, A.P.D. Emissão de gases de efeito 
estufa e proposta de projeto para compensação: um estudo de caso e-commerce. BIOFIX Scientific Journal, v.2, n.1, p.69-77, 2017.

PAIVA, A.O. et al. Estoque de carbono em cerrado sensu stricto do distrito federal. Revista Árvore, v.35, n.3, p.527-538, 2011.

PAROLIN, P.; FERREIRA, L.V. Are there differences in specific wood gravities between trees in várzea and igapó (Central Amazonia)? Ecotropica, v.4, p.25-32, 1998.

PAULA, J.E.D. et al. Levantamento quantitativo em três hectares de vegetação de Cerrado. Pesquisa Agropecuária Brasileira, v.33, n.5, p.613-620, 1998.

PBMC - PAINEL BRASILEIRO DE MUDANÇAS CLIMÁTICAS. Mitigação das mudanças climáticas. 1.ed. Rio de Janeiro, v.3, 2014.

REBOITA, M.S. et al. Climate projections for South America: RegCM3 Driven by HadCM3 and ECHAM5. Hindawi Publishing Corporation Advances in Meteorology, v.2014, p.1-17, 2014.

RESENDE, A.S.D. et al. Efeito estufa e o seqüestro de carbono em sistemas de cultivo com espécies florestais e na cultura de canade-açúcar. Embrapa Agrobiologia, n.133, p.1-23, 2001.

REZENDE, A.V. et al. Comparação de modelos matemáticos para estimativa do volume, biomassa e estoque de carbono da vegetação lenhosa de um cerrado sensu stricto em Brasília, DF. Scientia Forestalis, n.71, p.65-76, 2006.

SANO, S.M. et al. Baru: biologia e uso. 1.ed. Planaltina: Embrapa Cerrados, 2004.

SANQUETTA, C.R. et al. Floresta com araucária e suas transições: pesquisas ecológicas de longa duração. Curitiba: Pesquisas Ecológicas de Longa Duração (PELD/CNPq), 2014.

SERENO, L.G.F.; ANDRADE, D.C. Perfil regional e setorial das emissões brasileiras de gases de efeito estufa entre 1990 e 2017. Revista Iberoamericana de Economía Ecológica, v.32, n.1, p.2246, 2020.

SILVA, C.J.D. et al. Densidade básica da madeira de espécies arbóreas de Cerradão no estado de Tocantins. Pesquisa Florestal Brasileira, v.35, n.82, p.63-75, 2015.

SOARES, C.P.B. et al. Dendrometria e inventário florestal. 2.ed. Viçosa: UFV, 2012.

VALE, A.T.D. et al. Quantificação e caracterização energética da madeira e casca de espécies do Cerrado. Ciência Florestal, v.12, n.1, p.71-80, 2002.

VIEIRA, G. et al. Teores de carbono em espécies vegetais da caatinga e do Cerrado. Revista Acadêmica : Ciências Agrárias e Ambientais, v.7, n.2, p.145-155, 2009.

WILLIAMS, R.S. et al. Characteristics of ten tropical hardwoods from certified forests in Bolivia part i weathering characteristics and dimensional change. Wood and Fiber Science, v.33, n.4, p.618-626, 2001.
WOLF, R. et al. Sistemas agroflorestais: potencial para sequestro de carbono e produção de outros serviços ambientais. $4^{\circ}$ Seminário de Agroecologia de Mato Grosso do Sul, 2012.

Recebido em 20-09-2020

Aceito em 12-11-2020 